\title{
FIRE GROWTH RATE INDEX AS A KEY FIRE CHARACTERISTIC OF ELECTRICAL CABLES
}

\author{
Jozef MARTINKA $^{1 *}$, Peter RANTUCH ${ }^{1}$, Igor WACHTER ${ }^{1}$, Tomáš ŠTEFKO ${ }^{1}$, \\ Martin TRČKA ${ }^{2}$, Martina HLADOVÁ ${ }^{1}$, Aleš NEČAS ${ }^{1}$, Janka SULOVÁ ${ }^{3}$ \\ ${ }^{1}$ SLOVAK UNIVERSITY OF TECHNOLOGY IN BRATISLAVA \\ FACULTY OF MATERIALS SCIENCE AND TECHNOLOGY IN TRNAVA \\ INSTITUTE OF INTEGRAL SAFETY \\ Ulica JÁnA BotTu 2781/25, 91724 TRNAVA, SLOVAK REPUBliC \\ ${ }^{2}$ VSB TECHNICAL UNIVERSITY OF OSTRAVA, FACULTY OF SAFETY ENGINEERING \\ LuMíROVA 630/13, 70030 OSTRAVA - VÝŠKOVICE, CZECH REPUBLIC \\ ${ }^{3}$ VUKI, A.S., RYBNIČNÁ 38, 83107 BRATISLAVA, SLOVAK REPUBLIC \\ e-mail: jozef.martinka@stuba.sk, peter.rantuch@stuba.sk, igor.wachter@stuba.sk, \\ tomas.stefko@stuba.sk,martin.trcka@vsb.cz,martina.hladova@stuba.sk, \\ ales.necas@stuba.sk,sulova@vuki.sk \\ *corresponding author \\ Received 20 April 2021, Accepted 26 May 2021, Published 20 July 2021
}

\begin{abstract}
This study deals with the Fire Growth Rate Index (FIGRA) as a key fire characteristic of electrical cables (determined by a cone calorimeter) that allows to estimate their reaction to fire class. Three power (supply) electrical cables (reaction to fire class $B 2_{c a}$ ) were tested by a cone calorimeter using different heat fluxes of $20,30,40$ a $50 \mathrm{~kW} \cdot \mathrm{m}^{-2}$. The cables were threewire (cross-section of each wire was $1.5 \mathrm{~mm}^{2}$ ) with a nominal voltage of $0.6 \mathrm{kV}$ (alternating current), resp. $1 \mathrm{kV}$ (direct current). The cable sheaths were made of an ethylene copolymer filled with aluminum hydroxide. The beddings were made of an ethylene copolymer filled with a mixture of aluminum hydroxide and calcium carbonate. The conductor insulations of one electrical cable were made of crosslinked polyethylene and the conductor insulations of the other two electrical cables were made of an ethylene copolymer filled with aluminum hydroxide. FIGRA was determined per unit length and unit area of electrical cables. FIGRA increased with increasing heat flux. At a heat flux of $50 \mathrm{~kW} \cdot \mathrm{m}^{-2}$, all the electric cables examined showed a very similar FIGRA (from 0.19 to $0.21 \mathrm{~kW} \cdot \mathrm{m}^{-1} \cdot \mathrm{s}^{-1}$ and 18.4 to $21.2 \mathrm{~kW} \cdot \mathrm{m}^{-1} \cdot \mathrm{s}^{-1}$, respectively). Conversely, at a heat flux of $20 \mathrm{~kW} \cdot \mathrm{m}^{-2}$, the investigated cables showed greater FIGRA variance (in the range of 0.11 to $0.16 \mathrm{~kW} \cdot \mathrm{m}^{-1} \cdot \mathrm{s}^{-1}$ or 10.8 to $16.2 \mathrm{~kW} \cdot \mathrm{m}^{-1} \cdot \mathrm{s}^{-1}$ ).
\end{abstract}

\section{Keywords}

Cone calorimeter, heat release rate, electrical cable, fire growth rate index, reaction to fire class 


\section{INTRODUCTION}

Reaction to fire class is the most important fire characteristic of electrical cables. Electrical cables are classified into seven reactions to fire class $\left(\mathrm{A}_{\mathrm{ca}}, \mathrm{B} 1_{\mathrm{ca}}, \mathrm{B} 2_{\mathrm{ca}}, \mathrm{C}_{\mathrm{ca}}, \mathrm{D}_{\mathrm{ca}}, \mathrm{E}_{\mathrm{ca}}\right.$ and $\left.\mathrm{F}_{\mathrm{ca}}\right)$ according to EN 13501-6:2018 [1]. Electrical cables classified to reaction to fire class of $\mathrm{B} 1_{\mathrm{ca}}$ to $D_{\mathrm{ca}}$ obtain an additional classifications regarding smoke production (s1, s2 or s3 - higher number denotes much smoke production), flaming droplets production (d0, d1 and d2 - higher number means much flaming droplets production) and acidity of combustion products (a1, a2 and a3 - higher number indicates higher acidity).

A disadvantage of the reaction to fire class is that several tests are required to determine it, which are defined in EN 13501-6:2018 [1] (EN ISO 1716:2018 [2], EN 50399:2016 [3] and IEC $60332-1-2: 2015$ [4]) and the resulting time requirements and costs.

The minimum class of reaction to fire of uncovered electric cables in specific fire compartments in the Slovak Republic is determined by STN 92 0203:2013 [5]. The quoted STN implies that uncovered electrical cables in areas with the highest risk to human life and health (especially crèches, hospital wards, rooms in residential and accommodation buildings and protected escape routes) must have a reaction to fire class at least $\mathrm{B} 2_{\mathrm{ca}}, \mathrm{s} 1, \mathrm{~d} 1$, a1. From this point of view, the prediction of the reaction to fire class of $\mathrm{B} 2_{\mathrm{ca}}$ electric cables is of the greatest importance.

The results of scientific work [6] suggest that the reaction to fire class of electrical cables $\mathrm{B} 1_{\mathrm{ca}}$ and $\mathrm{B} 2_{\mathrm{ca}}$ (theoretically up to Dca) can be estimated from the Fire Growth Rate Index (hereinafter only FIGRA), which is calculated from the heat release rate measured by a cone calorimeter according to ISO 5660-1:2015 [7].

FIGRA from the data measured by the test according to EN 50399:2016 [3] is calculated according to equation (1) given by the quoted EN.

$$
\mathrm{FIGRA}=1000 \cdot \max \left[\frac{\mathrm{HRR}_{\mathrm{av}}}{t-t_{\mathrm{i}}}\right]
$$

where FIGRA is Fire Growth Rate Index $\left(\mathrm{W} \cdot \mathrm{s}^{-1}\right), \mathrm{HRR}_{\mathrm{av}}$ is 30 second average value of Heat Release Rate - hereinafter only HRR (kW), $t$ is time after ignition (s) and $t_{\mathrm{i}}$ is ignition time (s).

FIGRA is calculated from the heat release rate measured by a cone calorimeter equally according to equation (1) with two alternatives. In the alternative 1, FIGRA is calculated according to equation (1), without change. In alternative 2 (published in [6]), the FIGRA is calculated from the 15-second average value of the heat release rate. Both alternatives have two options. The option 1 is to calculate FIGRA per unit area (per $1 \mathrm{~m}^{2}$ ) or per unit length of electrical cables (per $1 \mathrm{~m}$ ). According to [6], FIGRA has a higher information value for the electric cable, calculated from the 15-second average value of the heat release rate per unit length (than per unit area).

For classification into reaction to fire class B2 $2_{\mathrm{ca}}$, EN 13501-6:2018 [1] is required when tested according to EN 50399:2016 [3] FIGRA $\leq 150 \mathrm{~W} \cdot \mathrm{s}^{-1}$. The FIGRA values determined by the method according to EN 50399:2016 [3] and by the cone calorimeter according to ISO 5660-1:2015 [7] are not directly comparable (due to different way of cable ignition and configuration during the test). The following procedure has a significantly higher informative value. In step 1 , the FIGRA interval of electrical cables of reaction to fire class $\mathrm{B} 2 \mathrm{ca}$ is determined by the cone calorimeter. Subsequently, in step 2, the FIGRA of the electrical cable is determined (which is preliminarily verified whether or not it meets the requirements for classification into reaction to fire class $\mathrm{B} 2 \mathrm{ca}$ ). If the FIGRA of the verified cable is within the FIGRA interval specified for electrical cables with a reaction to fire class of $\mathrm{B} 2_{\mathrm{ca}}$, there is a high probability that the verified cable meets the requirements for classification into a reaction 
to fire class $\mathrm{B} 2_{\mathrm{ca}}$ (when tested according to EN 50399:2016 [3]). This preliminary test can significantly reduce the cost of testing electrical cables with the method according to EN 50399:2019 [3]. At present, however, very few scientific papers have been published (e.g. [6]) in which the FIGRA of electrical cables of reaction to fire class $\mathrm{B} 2_{\mathrm{ca}}$ by the cone calorimeter has been determined.

The aim of the presented research is to determine the FIGRA interval of three different power electric cables of reaction to fire class $\mathrm{B} 2_{\text {ca }}$ tested by the cone calorimeter according to ISO 5660-1:2015 [7] with heat fluxes in the interval 20 to $50 \mathrm{~kW} \cdot \mathrm{m}^{-2}$. The second aim is to assess the statistical significance of FIGRA differences between the investigated electrical cables.

\section{MATERIALS AND METHODOLOGY}

Three power electric cables were investigated. All examined cables were classified in the reaction to fire class $\mathrm{B} 2 \mathrm{ca}$ and consisted of three insulated copper conductors (wires) with a cross-section of $1.5 \mathrm{~mm}^{2}$, bedding and a sheath. The insulation, bedding and sheath were made of halogen-free polymers. The nominal voltage of the examined cables was $600 \mathrm{~V}$ (alternating current), resp. $1000 \mathrm{~V}$ (direct current). The first electric cable marked N2XH J3x1.5 RE was manufactured by ELKOND HHK, a.s. (Trstená, Slovakia). The polymer components of the $\mathrm{N} 2 \mathrm{XH}$ cable (insulation, bedding and sheath) are based on polyethylene (insulation) and its copolymers (sheath and bedding). The polymer component of the sheath was filled with aluminum hydroxide and the polymer component of the bedding was filled with aluminum hydroxide and calcium carbonate (filler content was over $80 \%$ by weight). The second and third electric cables were manufactured and supplied by VUKI, a.s. (Bratislava, Slovakia). These cables were designated CHKE-R J3×1.5 and CHKE-V J3x1.5 E30 (the CHKE-V cable shows circuit integrity under fire conditions for 30 minutes). The polymer components (insulation, bedding and sheath) of these cables were based on polyethylene copolymers. The polymer component of both the insulation and the sheath was filled with aluminum hydroxide and the polymer component of the bedding was filled with a mixture of aluminum hydroxide with calcium carbonate (filler content was over $80 \%$ by weight).

The heat release rate from the investigated cables was determined by the cone calorimeter according to ISO 5660-1: 2015 [7] at heat fluxes of 20, 30, 40 and $50 \mathrm{~kW} \cdot \mathrm{m}^{-2}$. The orientation of the samples and the cone heater during the test was horizontal. The arrangement of the samples on the sample holder during the test is illustrated in Fig. 1. FIGRA was calculated per unit area and unit length of the examined electric cables. FIGRA was calculated according to the equation (1) from fifteen second average heat release rates (HRR). All HRR values measured in the time interval from $5 \mathrm{~s}$ after initiation to the end of the test were included in the calculation.

The diameters of the examined cables were as follows: $\mathrm{N} 2 \mathrm{XH}(10 \mathrm{~mm}$ : during the test, 10 samples were placed next to each other on a holder measuring $100 \times 100 \mathrm{~mm}$ ), CHKE-R ( $8 \mathrm{~mm}$ : during the test 12 samples were placed next to each other on a $100 \times 100 \mathrm{~mm}$ holder) and CHKE-V (9 mm: during the test, 11 samples were placed next to each other on a $100 \times 100 \mathrm{~mm}$ holder).

The statistical significance of the difference in FIGRA between the investigated electrical cables was evaluated by the method of mathematical statistics Analysis of Variance (ANOVA) at a significance level $\alpha=0.05$. 


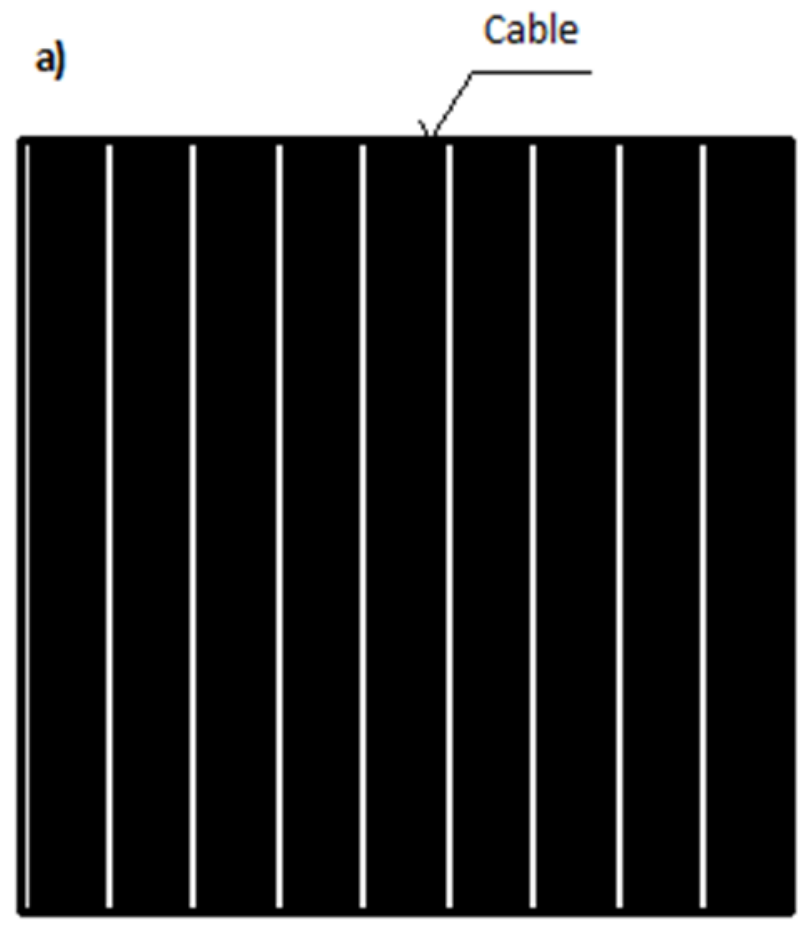

b)

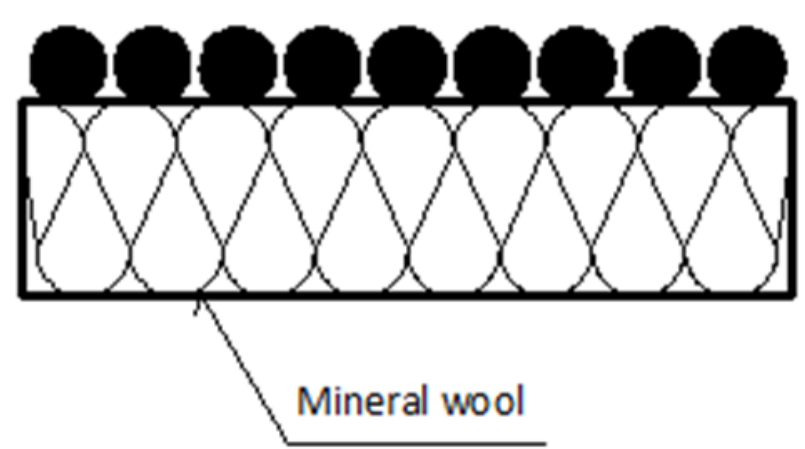

Figure 1 Configuration of investigated cables during the cone calorimeter test a) view from the above; b) cross-section

\section{RESULTS AND DISCUSSION}

Fire growth rate index of the investigated electrical cables is shown in Table 1 (per unit of area) and in Table 2 (per unit of length). 


\begin{tabular}{|c|c|c|}
\hline \multicolumn{3}{|c|}{$\begin{array}{l}\text { Table } 1 \text { Fire growth rate index (per unit of area) } \\
\text { of investigated cables }\end{array}$} \\
\hline $\begin{array}{l}\text { Sample } \\
(-)\end{array}$ & $\begin{array}{l}\text { Heat flux } \\
\left(\mathbf{k W} \cdot \mathbf{m}^{-2}\right)\end{array}$ & $\begin{array}{l}\text { FIGRA } \\
\left(\mathbf{k W} \cdot \mathbf{m}^{-2} \cdot \mathbf{s}^{-1}\right)\end{array}$ \\
\hline \multirow{4}{*}{ CHKE-V } & 20 & $16.2 \pm 0.1$ \\
\hline & 30 & $18.4 \pm 2.2$ \\
\hline & 40 & $19.7 \pm 1.8$ \\
\hline & 50 & $21.2 \pm 0.2$ \\
\hline \multirow{4}{*}{ CHKE-R } & 20 & $15 \pm 0.9$ \\
\hline & 30 & $15.9 \pm 1.0$ \\
\hline & 40 & $17.6 \pm 0.3$ \\
\hline & 50 & $19.9 \pm 0.8$ \\
\hline \multirow{4}{*}{$\mathrm{N} 2 \mathrm{XH}$} & 20 & $10.8 \pm 1.2$ \\
\hline & 30 & $13.2 \pm 0.8$ \\
\hline & 40 & $18.5 \pm 1.2$ \\
\hline & 50 & $18.4 \pm 1.4$ \\
\hline
\end{tabular}

\begin{tabular}{|l|l|l|}
\hline \multicolumn{3}{|l|}{$\begin{array}{l}\text { Table 2 Fire growth rate index (per unit of length) } \\
\text { of investigated cables }\end{array}$} \\
\hline $\begin{array}{l}\text { Sample } \\
(-)\end{array}$ & $\begin{array}{l}\text { Heat flux } \\
\left(\mathbf{k W} \cdot \mathbf{m}^{-2}\right)\end{array}$ & $\begin{array}{l}\text { FIGRA } \\
\left(\mathbf{k W} \cdot \mathbf{m}^{-2} \cdot \mathbf{s}^{-\mathbf{1}}\right)\end{array}$ \\
\hline \multirow{5}{*}{ CHKE-V } & 20 & $0.16 \pm 0.01$ \\
\cline { 2 - 3 } & 30 & $0.18 \pm 0.02$ \\
\hline \multirow{5}{*}{ CHKE-R } & 40 & $0.20 \pm 0.02$ \\
\hline \multirow{5}{*}{ N2XH } & 50 & $0.21 \pm 0.01$ \\
\hline \multirow{5}{*}{} & 20 & $0.14 \pm 0.01$ \\
\hline & 30 & $0.15 \pm 0.01$ \\
\hline & 50 & $0.17 \pm 0.01$ \\
\hline & 20 & $0.19 \pm 0.01$ \\
\hline & 30 & $0.11 \pm 0.01$ \\
\hline & 40 & $0.13 \pm 0.01$ \\
\hline & 50 & $0.18 \pm 0.01$ \\
\hline
\end{tabular}


The data in Tables 1 and 2 show that at a heat flux of $50 \mathrm{~kW} \cdot \mathrm{m}^{-2}$, the investigated electrical cables show only slight differences in FIGRA (interval from 18.4 to $21.2 \mathrm{~kW} \cdot \mathrm{m}^{-2} \cdot \mathrm{s}^{-1}$ per unit area, respectively 0.19 to $0.21 \mathrm{~kW} \cdot \mathrm{m}^{-1} \cdot \mathrm{s}^{-1}$ per unit length). Similarly, at a heat flux of $40 \mathrm{~kW} \cdot \mathrm{m}^{-}$ ${ }^{2}$, the differences in FIGRA are negligible. With decreasing heat flux, the differences between FIGRA of the investigated electric cables increased (at a heat flux of $20 \mathrm{~kW} \cdot \mathrm{m}^{-2}$, FIGRA was in the range of 10.8 to $16.2 \mathrm{~kW} \cdot \mathrm{m}^{-2} \cdot \mathrm{s}^{-1}$ per unit area, or 0.11 to $0.16 \mathrm{~kW} \cdot \mathrm{m}^{-1} \cdot \mathrm{s}^{-1}$ per unit length). It follows that for the prediction of the reaction to fire class from FIGRA determined by the cone calorimeter, the data measured at heat fluxes of 40 and $50 \mathrm{~kW} \cdot \mathrm{m}^{-2}$ (as at heat fluxes of 20 and $30 \mathrm{~kW} \cdot \mathrm{m}^{-2}$ ) have a higher predictive value. Comparable FIGRA values (from 0.12 to 0.15 $\mathrm{kW} \cdot \mathrm{m}^{-1} \cdot \mathrm{s}^{-1}$, at a heat flux of $50 \mathrm{~kW} \cdot \mathrm{m}^{-2}$ ) of electrical cables classified in reaction to fire class $\mathrm{B} 2_{\mathrm{ca}}$ have been published in scientific paper [6]. Comparison of FIGRA values with the results of other scientific papers is problematic (as a very few papers have determined FIGRA of electrical cables from values measured on the cone calorimeter). The second reason for the problematic comparison of FIGRA values with the results of other works is the fact that these scientific papers report different methods for FIGRA determination (e.g. in study [8], FIGRA is calculated as the ratio of the maximum heat release rate to the time when this value was reached). The third reason is the already mentioned difference between the FIGRA values determined from the results of the heat release rate measured by different test methods. The last reason is the fact that in the case of electric cables, FIGRA has the highest informative value per unit of length (per $1 \mathrm{~m}$ ), while for solid materials, FIGRA is almost exclusively determined per unit area $\left(\right.$ per $1 \mathrm{~m}^{2}$ ). These facts are the cause of the relatively large dispersion of FIGRA, e.g. from scientific papers [8-10] it follows that FIGRA of synthetic polymers (depending on their chemical composition, content and type of flame retardants and method of determination) can differ by up to several orders of magnitude: from tenths to tens of $\mathrm{kW} \cdot \mathrm{m}^{-2} \cdot \mathrm{s}^{-1}$ ). The FIGRA values can therefore only be compared if the heat release rate was determined on the same type of test equipment under identical conditions (in particular heat flux) and the same calculation method was used. From this point of view, it is correct to compare the results presented in Table 1 with the results of study [6]. However, a high degree of caution should be maintained when comparing the data obtained with the results of other scientific works (in which FIGRA has been determined by other test methods or other calculation procedures).

The statistical significance of FIGRA differences, between the examined cables was assessed by Analysis of Variance (ANOVA) at a significance level of $\alpha=0.05$. The obtained parameters $p=0.9845, F=0.016$ and $F_{\text {crit }}=3.467$ prove that the differences in FIGRA of the examined electrical cables are not statistically significant.

FIGRA of the examined electric cables, powered to $-1 / 2$, shows almost linear dependence on the heat flux in the interval 20 to $50 \mathrm{~kW} \cdot \mathrm{m}^{-2}$ (Fig. 2 and Fig. 3). Fig. 2 shows the dependence of FIGRA ${ }^{-1 / 2}$ (per unit of length of investigated cables) on heat flux, and Figure 3 shows the dependence of FIGRA ${ }^{-1 / 2}$ (per unit of area of investigated cables) on heat flux. 

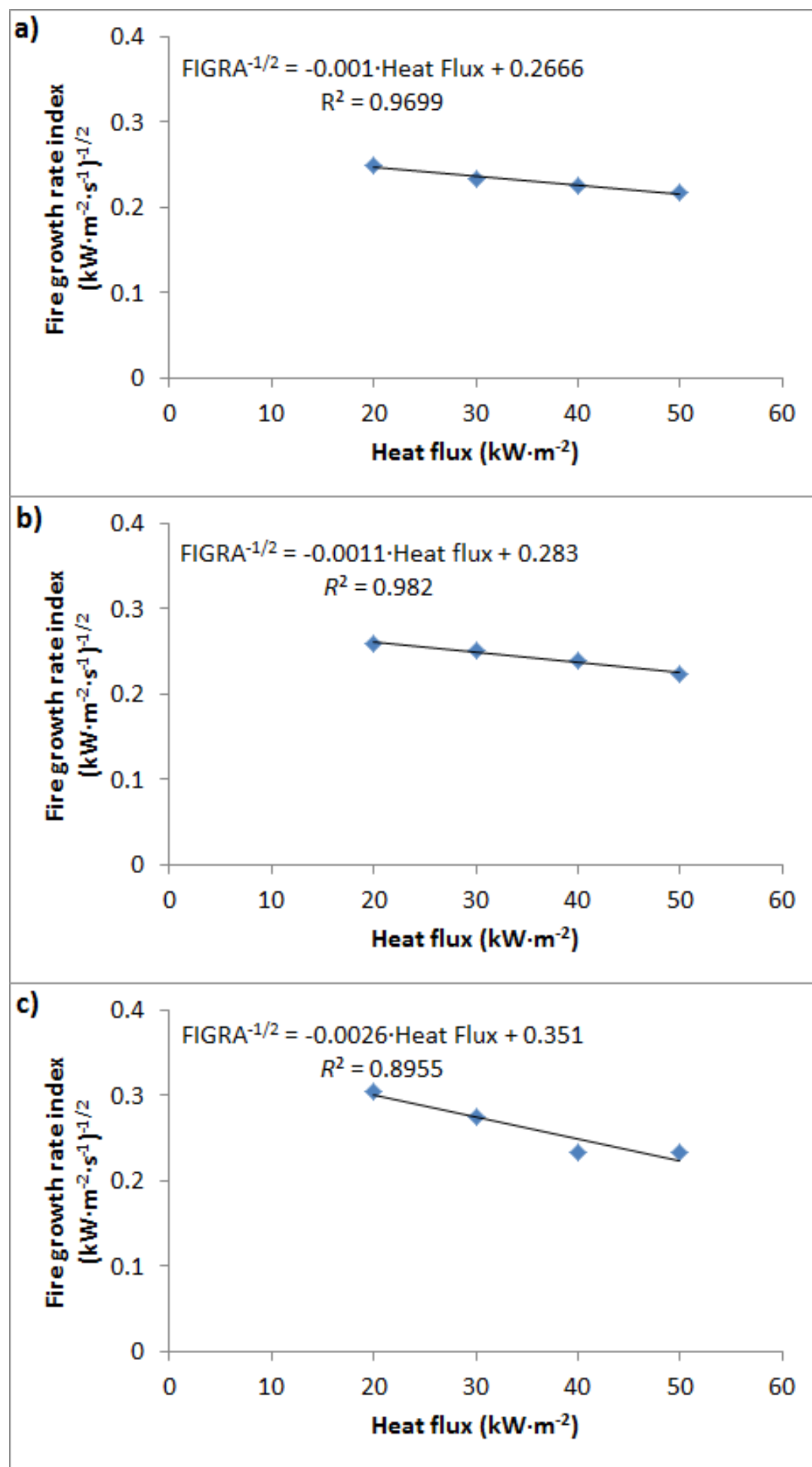

Figure 2 Dependence of fire growth rate index (per unit of area) powered to $-1 / 2$ on the heat flux of investigated cables: a) CHKE-V; b) CHKE-R; c) N2XH 

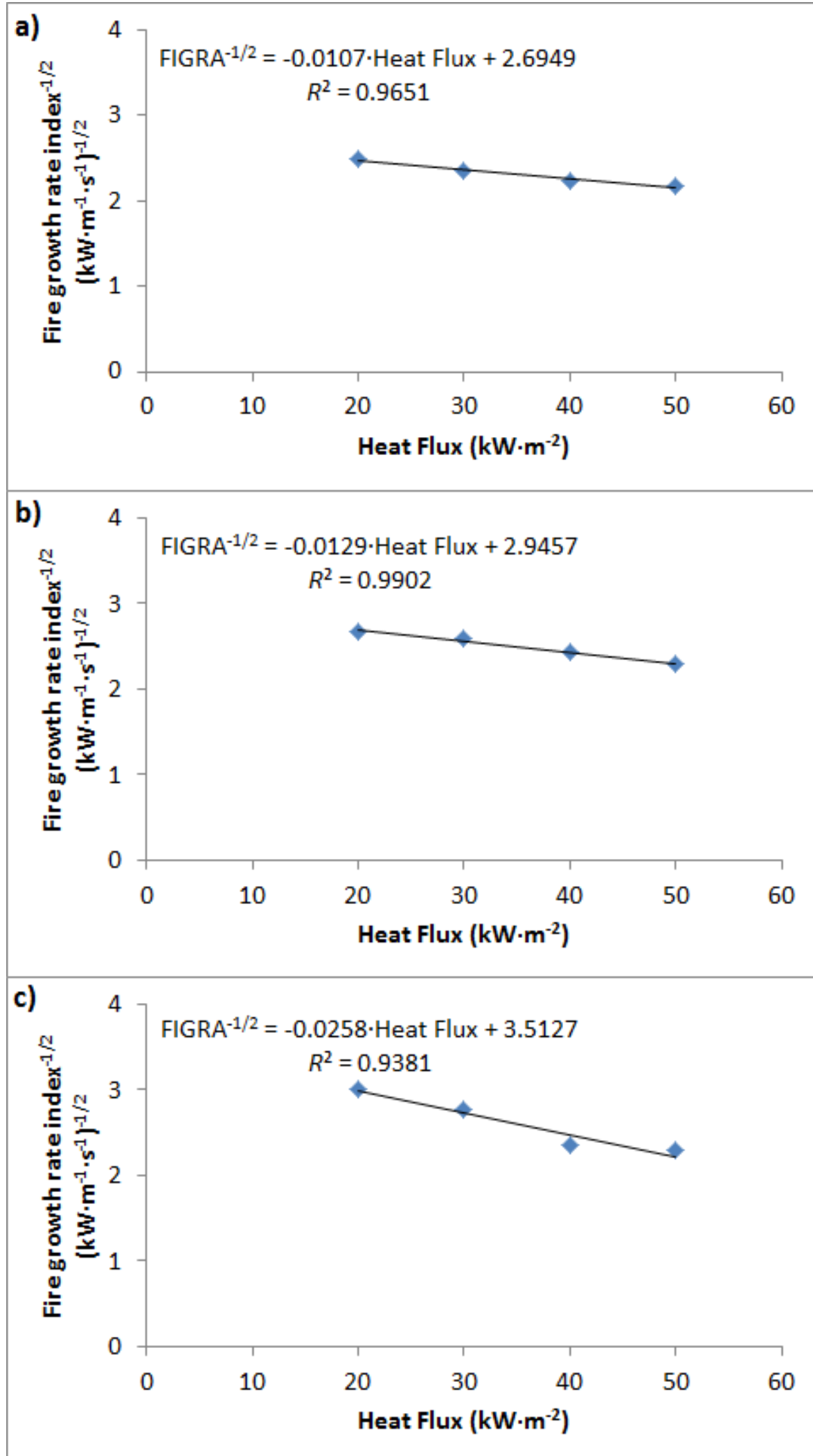

Figure 3 Dependence of fire growth rate index (per unit of length) powered to $-1 / 2$ on the heat flux of investigated cables: a) CHKE-V; b) CHKE-R; c) N2XH 
Figs 2 and 3 together with Tabs 1 and 2 show a lower FIGRA value of the N2XH cable at lower heat fluxes $\left(20\right.$ and $\left.30 \mathrm{~kW} \cdot \mathrm{m}^{-2}\right)$ than those of the CHKE-R and CHKE-V electric cables. The reason is the lower maximum heat release rate from the $\mathrm{N} 2 \mathrm{HX}$ cable just after initiation (lower local maximum heat release rate after initiation) than from the other investigated cables (CHKE-R and CHKE-V). In addition to the prediction of the reaction to fire class, the FIGRA parameter is an important characteristic for predicting the fire dynamics in areas where cables or synthesis polymers form a significant part of the fire load (e.g. cars, tunnels, and server rooms), further details are described in [11-14].

From the above-mentioned it follows that if FIGRA of a three-wire electric cable (with a conductor cross-section of $1.5 \mathrm{~mm}$ ) equals to or is less than $0.21 \mathrm{~kW} \cdot \mathrm{m}^{-2} \cdot \mathrm{s}^{-1}$ (determined as described in the materials ad methodology chapter), it is highly likely that it meets the requirements for classification in reaction to fire class $\mathrm{B} 2_{\text {ca. }}$.

\section{CONCLUSION}

In the present contribution, FIGRA of three different power electrical cables (reaction to fire class B2 $2_{\text {ca }}$ ) was determined. The obtained data prove that at heat flux of 40 and $50 \mathrm{~kW} \cdot \mathrm{m}^{-2}$ all investigated cables show almost identical FIGRA value. At heat fluxes of 20 and $30 \mathrm{~kW} \cdot \mathrm{m}^{-2}$, the differences between FIGRA of the investigated cables were more significant. Nevertheless, the results of ANOVA (at the significance level $\alpha=0.05$ ) prove that the obtained FIGRA values of the examined cables do not show statistically significant differences in the whole range of heat fluxes $\left(20\right.$ to $\left.50 \mathrm{~kW} \cdot \mathrm{m}^{-2}\right)$.

However, the conclusions above are valid under the conditions used during the experiment (the cone calorimeter at a heat flux of 20 to $50 \mathrm{~kW} \cdot \mathrm{m}^{-2}$ ), the method of calculating FIGRA (maximum value of the ratio of 15-seconds average HRR values (at intervals of $5 \mathrm{~s}$ after initiation until the end of the test) to the time after ignition) and the types of investigated electrical cables (three-wire power supply cable with a cross-section of $1.5 \mathrm{~mm}^{2}$, reaction to fire class $\mathrm{B} 2_{\mathrm{ca}}$, with polymer components based on ethylene or its copolymers). For this type of electrical cable, the FIGRA value determined in this way allows a preliminary (indicative) prediction of the reaction to fire class.

\section{Acknowledgement}

This research was supported by the Slovak Research and Development Agency under the contract No.APVV-16-0223.

\section{References}

[1] EN 13501-6:2018. Fire classification of construction products and building elements - Part 6: Classification using data from reaction to fire tests on power, control and communication cables.

[2] EN ISO 1716:2018. Reaction to fire tests for products - Determination of the gross heat of combustion (calorific value).

[3] EN 50399:2011+A1:2016. Common test methods for cables under fire conditions. Heat release and smoke production measurement on cables during flame spread test. Test apparatus, procedures, results.

[4] IEC 60332-1-2:2004+AMD1:2015 CSV. Tests on electric and optical fibre cables under fire conditions - Part 1-2: Test for vertical flame propagation for a single insulated wire or cable Procedure for $1 \mathrm{~kW}$ pre-mixed flame.

[5] STN 92 0203:2013/O1:2013. Požiarna bezpečnost' stavieb. Trvalá dodávka elektrickej energie pri požiari (Fire safety of buildings. Permanent electricity supply during fire). 
[6] MARTINKA, J., RANTUCH, P., SULOVÁ, J., MARTINKA, F. 2019. Assessing the fire risk of electrical cables using a cone calorimeter. Journal of Thermal Analysis and Calorimetry, 135(6), 3069-3083. ISSN 1388-6150.

[7] ISO 5660-1:2015. Reaction to fire tests. Heat release, smoke production and mass loss rate - Part 1: Heat release rate (cone calorimeter method) and smoke production rate (dynamic measurement).

[8] PARK, J., W., LIM, O., K., YOU, W., J. 2020. Analysis on the Fire Growth Rate Index Considering of Scale Factor, Volume Fraction, and Ignition Heat Source for Polyethylene Foam Pipe Insulation. Energies, 13(14), 1-15, ISSN 1996-107.

[9] WANG, D-Y., LIU, Y., WANG, Y-Z., ARTILES, C., P., HULL, T., R., PRICE, D. $2007 . \quad$ Fire retardancy of a reactively extruded intumescent flame retardant polyethylene system enhanced by metal chelates. Polymer Degradation and Stability, 92, 1592-1598, ISSN 0141-3910.

[10] WANG, Y., KANG, W., CHEN, C. et al. 2019. Combustion behaviour and dominant shrinkage mechanism of flexible polyurethane foam in the cone calorimeter test. Journal of Hazardous Materials, 365, 395-404, ISSN 0304-3894.

[11] SVETLÍK, J., VEL'AS, A. 2017. Vehicle fire safety of the static traffic. In Transport Means Proceedings of the International Conference. The 21st International Scientific Conference Transport Means: Lithuania, Kaunas, pp. 636-639. ISSN 1822-296X.

[12] AN, W., WANG, T., LIANG, K., TANG, Y., WANG, Z. 2020. Effects of interlayer distance and cable spacing on flame characteristics and fire hazard of multilayer cables in utility tunnel. Case Studies in Thermal Engineering, 22, DOI: 10.1016/j.csite.2020.100784, ISSN 2214-157X.

[13] XU, Q., JIN, C., MAJLINGOVA, A., ZACHAR, M., RESTAS, A. 2019. Evaluate the flammability of a PU foam with double-scale analysis. Journal of Thermal Analysis and Calorimetry, 135(6), 3329-3337, ISSN 1388-6150.

[14] LI, J., HE, S., WANG, T., SHEN, Z., CHEN, X., ZHOU, F. 2021. A catalyst powder-based spraying approach for rapid and efficient removal of fire-generated CO: From laboratory to pilot scale. Journal of Hazardous Materials, 415, 1-12, ISSN 0304-3894.

\section{ORCID}

$\begin{array}{ll}\text { Jozef Martinka } & 0000-0002-0060-5785 \\ \text { Peter Rantuch } & 0000-0001-5826-8323 \\ \text { Igor Wachter } & 0000-0003-0691-0462 \\ \text { Tomáš Štefko } & 0000-0002-3975-6775 \\ \text { Martin Trčka } & 0000-0002-4574-229 X \\ \text { Martina Hladová } & 0000-0003-4281-9834 \\ \text { Aleš Nečas } & 0000-0003-3626-7092\end{array}$

